\title{
Assessment of the level and associated factors with knowledge and practice of Diabetes Mellitus among Diabetic Patients attending at FelegeHiwot Hospital, Northwest Ethiopia
}

\author{
Solomon Asnakew Feleke ${ }^{1,}$, , Chalachew Misganaw Alemayehu ${ }^{2}$, Hawult Taye Adane ${ }^{2}$ \\ ${ }^{1}$ Medicine San Frontiers (MSF), Addis Ababa, Ethiopia \\ ${ }^{2}$ Clinical Trial Department, ArmauerHansen Research Institute (AHRI), Ethiopia
}

\section{Email address:}

agsolo2012@gmail.com(S. A. Feleke), bestchale@yahoo.com(C. M. Alemayehu), chaleg202003@gmail.com(C. M. Alemayehu), hawultt@yahoo.com (H. T. Adane)

\section{To cite this article:}

Solomon Asnakew Feleke, Chalachew Misganaw Alemayehu, Hawult Taye Adane. Assessment of the Level and Associated Factors with Knowledge and Practice of Diabetes Mellitus among Diabetic Patients Attending at FelegeHiwot Hospital, Northwest Ethiopia. Clinical Medicine Research. Vol. 2, No. 6, 2013, pp. 110-120. doi: 10.11648/j.cmr.20130206.11

\begin{abstract}
Introduction: Diabetes mellitus was perceived as the problem of the developed world but currently developing countries like Ethiopia are suffering chronic diseases of which diabetes is the major one.Objective: The aim of this study wasto assess of the level and associated factors with knowledge and practice of diabetes mellitus among diabetic patients attending at FelegeHiwot hospital. Methods: Institution based cross sectional study was conducted using interviewer administered questionnaire among 410 diabetic patients. Systematic sampling technique was used to select study subjects. Data was entered to EPI info 3.5.1 and then transferred to SPSS for analysis. Descriptive and analytical statistics including bivariate and multivariate analysis were applied. Result: Among 410 respondents, Half $(49.8 \%)$ of them had good knowledge and one hundred fifty four (36.8\%) participants had good practice on diabetes. Lower age was significantly associated with good knowledge and practice. Age group 18-32 yrs, 33-41 yrs and 42-50 yrs were 6.2 times, 3.3 times and 3.1 times respectively more likely to had good knowledge compared to individuals who were at the age of 50 yrsand above. Similarly, age group between 18-32 yrs was 6 times more likely to have good practice. Higher educational status was also associated with good knowledge and practice. Participants in grade 1-8, grade 9-12 and higher education and above were 3.4 times, 4.7 times and 7.2 timesrespectively more likely to had good knowledge compared to those who were unable to read and write.Likewise, those in grade 1-8, grade 9-12 and higher education and above were 3.5, 4.3 and5.4 times respectivelyto have good practice.Increased duration of diabetic therapy was positively associated with good knowledge and practice. Increased level of income was positively associated with good practice.Conclusion: This study demonstrated low level of knowledge and practice among DM patients. Age, educational status and duration of DM therapy were associated with good knowledge and practice of participants. Monthly income was also associated with good practice. Improving knowledge and practice of diabetic patient through active education is advisable. Involvement of both governmental and non-governmental organizations is also crucial to help patients receive maximum benefit from the health care service.
\end{abstract}

Keywords: Diabetes Mellitus, Knowledge, Practice, Factors

\section{Introduction}

The burden of diabetes and diabetic related mortality and disability are rising in Africa. Increasing sedentary lifestyles, coupled with rapidly growing urban cultures and modified diets, are predicted to triple the prevalence of diabetes mellitus in the next 25 years $(1,2)$.
Ethiopia is the second most populous country in subSaharan Africa where more than $80 \%$ of the population lives in the country side. The country experiences a heavy burden of disease mainly attributed to communicable infectious diseases and nutritional deficiencies. Currently, 
Ethiopia is also challenged by the growing magnitude of chronic non communicable diseases. Despite major progresses in education, the literacy status of the population of Ethiopia is still low with total adult literacy rate of $36 \%$ (62\% for male and $39 \%$ for female).The education level in the country is still a significantly marker influencing the spread of disease, shaping the health seeking behavior of individuals and communities including the utilization of modern health care service (3).

In Ethiopia, national data on prevalence and incidence of diabetes are lacking. However, patient attendance rates and medical admissions in major hospitals are rising. The estimated prevalence of DM in adult population of Ethiopia is $1.9 \%(4,5)$. Moreover, Cohen et al reported a high prevalence of diabetes $(8.9 \%)$ among young (age $<30$ years) in Ethiopian Jews who have been to Israel for less than 4 years (6).WHO estimated the number of diabetic cases in Ethiopia to be 800,000 by the year 2000, and the number is expected to increase to 1.8 million by 2030(7).

Due of the nature of the disease, health professionals alone can't provide high quality care. Diabetes being a chronic illness requires sound knowledge of self-care by patients so that they can contribute meaningfully in the management of their lives .Control of the DM through a tight schedule of blood glucose and urine sugar monitoring, medication and adjustment to dietary condition need patient's regular attention and discipline. The disease condition requires competent self-care, which can be developed from a thorough under-standing of the disease process and the management challenges by the patient and family members. As a result of this, diabetic education and counseling for the patient and family members are becoming important goals of diabetic patients care today. Unfortunately, about a third of the people suffering from diabetes may not be aware of it early considering the insidious onset and development $(7,8)$.

Knowledge and practice study are therefore necessary in providing baseline evidence for evaluating intervention programs and to design future programs and techniques for effective health education (9). Especially such evidences are highly relevant in countries like Ethiopia where there is high level of illiteracy rate and where most people are rural residents as the findings from such studiesmay help in identifying diabetic patient's knowledge and practice gaps which will guide the development of prevention programs in the country. Hence the purpose of this study was to assess the patient's knowledge, practice and associated factors of diabetes mellitus among diabetic's people.

\section{Objective}

\subsection{General Objective}

- To assess of the level and associated factors with knowledge and practice of diabetes mellitus among diabetic patients attending at FelegeHiwot hospital, Northwest Ethiopia, North West Ethiopia

\subsection{Specific Objectives}

- To determine level of knowledge regarding diabetes among diabetic people

- To determine practice of diabetic people on diabetes mellitus

- To identify factors associated with knowledge of diabetes mellitus

- To identify factors associated with practice on diabetes mellitus

\section{Methods}

\subsection{Study Design and Period}

Institution based cross sectional study was conducted from July 2012-August 2012

\subsection{Study Area}

Bahir-dar is a capital city of Amhara region and located $565 \mathrm{kms}$ from Addis Ababa, North west Ethiopia. Based on central statistical agency in 2010 this city has an estimated total population of 274,836 . Felege Hiwot hospital is the only government hospital in the city and it is the regional referral hospital serving the population in the region as referral center.

\subsection{Population}

The source populations were all diabetics' patients who have follow up in Felege Hiwot hospital in Bahir-dar town. The study populations were all diabetics' patients who were coming to Felege Hiwot hospital for follow up during the study period.

\subsubsection{Inclusion and Exclusion Criteria}

All diabetics' patients aged $\geq 18$ years were included in the study. Patients who were severely ill and not able to communicate were excluded from the study.

\subsection{Sample Size and Sampling Procedure}

The sample size was determined by EPI INFO statcalc using a single population proportion formula by considering $50 \%$ proportion and $.5 \%$ marginal error. The sample size becomes 384 and adding $10 \%$ for non-response rate the final sample size is 422 .Systematic sampling technique was used to select study participants based the flow rate of patients during the study period.

\subsection{Variables of the Study}

Knowledge and practice of patients regarding diabetes are dependent variables. Independent variables include socio-demographic variables (age, sex, income, marital status, education, religion, occupation, and ethnicity) and health profile related variables (duration of treatment, type of medication used, co morbidity, DM association membership, family history of diabetics, Types of DM) 


\subsection{Operational Definition}

Regular checkup: All patients who were undertaking investigations within one month. Those who were undertaking check up with in one month or less given a score of one and otherwise zero (9).

Regular exercise: $20 \mathrm{~min}$ - 30 minutes of aerobic exercise such as walking or swimming 3-4 days per week(17).

Good Knowledge: when patients respond themean or above the mean score on knowledge questions.

Poor Knowledge: when patients respond below the mean score on knowledge questions.

Good Practice: when patients respond the mean or above the mean score on practice questions.

Poor practice: when patients respond below the mean score on practice questions.

\subsection{Data Collection Procedures}

The data were collected by six diploma nurses using structured and pre tested questionnaire The data collectors were given two days training on data collection techniques before starting data collection. The knowledge and practice questionnaire was adapted from Medi media USA (16) and has been used in previous Knowledge and practice studies among diabetics and has proven to be reliable in other countries. It had been pretested on 21 diabetic patients in a similar set up and modified as necessary for clarity, sensitiveness and completeness. Data regarding knowledge and practices related to DM,socio -demographic variables such as age, sex, income, marital status, education, religion, occupation, ethnicity, health profile variables such as family history of diabetic's, duration of diabetics, duration of treatment, co morbidity, DM association membership were collected. A scoring system was developed for each knowledge and practice questions. The knowledge part of the questionnaire have 11 questions with a maximum of 29 correct response which was calculated by given one for each correct response and zero for each wrong response. The practice part of the questionnaire have 8 questions with a maximum of 8 correct responses which was calculated by given one for patients having regular checkup and life style practice and zero for not. Two categories were defined on the bases of the score obtained by each participant: Good (greater than or equal to the mean of knowledge or practice score) and poor (less than the mean of knowledge or practice score).

\subsection{Data Quality Control Measures}

The questionnaire was pre-tested for their accuracy and consistency prior to actual data collection. Furthermore, the supervisor and the principal investigator gave feedback and corrections on daily basis to the data collectors. Completion, accuracy, and clarity of the collected data were checked carefullyon aregularly basis.

\subsection{Data Processing and Analysis}

The collected data was checked for its completeness and entered to EPI info 3.5.1 and then transferred to SPSS for analysis. Descriptive and analytical statistics including bivariate and multivariate analysesweredone. Proportion, percentage, ratios, frequency distribution, measure of central tendency and measure of dispersion were used to describe data on knowledge and practice.Bivariate analysis and chi- square test weredone to examine association between dependent and independent variables (socio demographic variables and health profile variables); after running logistic regression, all variables with $p<0.2$ were entered in to the final model and corresponding p-value of $<0.05$ was considered statistically significant. To identify the independent factor that influences knowledge and practice towards DM, multivariate logistic regression analysis was carried out.

Table 1: Socio demographic characteristics of participants, FHH, 2012

\begin{tabular}{|c|c|c|}
\hline Variable & Frequency & Percent \\
\hline \multicolumn{3}{|l|}{ Age } \\
\hline $18-32$ & 105 & 25.6 \\
\hline $33-41$ & 93 & 22.7 \\
\hline $42-50$ & 106 & 25.9 \\
\hline$\geq 51$ & 106 & 25.9 \\
\hline \multicolumn{3}{|l|}{ Sex } \\
\hline Male & 198 & 48.3 \\
\hline Female & 212 & 51.7 \\
\hline \multicolumn{3}{|l|}{ Religion } \\
\hline Orthodox & 363 & 88.5 \\
\hline Muslim & 40 & 9.8 \\
\hline Others & 7 & 1.7 \\
\hline \multicolumn{3}{|l|}{ Ethnic group } \\
\hline Amhara & 358 & 87.3 \\
\hline Tigray & 42 & 10.2 \\
\hline Oromo & 6 & 1.5 \\
\hline Others & 4 & 1.0 \\
\hline \multicolumn{3}{|l|}{ Marital status } \\
\hline Married & 324 & 79.0 \\
\hline Single & 47 & 11.5 \\
\hline Divorced/Widowed & 39 & 9.5 \\
\hline \multicolumn{3}{|l|}{ Educational status } \\
\hline Unable to read and write & 57 & 13.9 \\
\hline Read and write & 53 & 12.9 \\
\hline Grade 1-8 & 121 & 29.5 \\
\hline Grade 9-12 & 104 & 25.4 \\
\hline $\begin{array}{l}\text { Higher education and } \\
\text { above }\end{array}$ & $\begin{array}{l}104 \\
75\end{array}$ & $\begin{array}{l}25.4 \\
18.3\end{array}$ \\
\hline \multicolumn{3}{|l|}{ Work status } \\
\hline Civil servant & 77 & 18.8 \\
\hline Merchant & 127 & 31 \\
\hline Daily laborer & 22 & 5.4 \\
\hline House wife & 48 & 11.7 \\
\hline Farmer & 136 & 33.2 \\
\hline \multicolumn{3}{|l|}{ Monthly income(in birr) } \\
\hline$\leq 500$ & 205 & 50 \\
\hline$>500$ & 205 & 50 \\
\hline
\end{tabular}

\subsection{Ethical Consideration}

Ethical approval and clearance was obtained from Institutional Review Board of University of Gondar prior to enrolment. Permission to conduct the study was obtained 
from FelegeHiwot Hospital prior to data collection. Objective of the study was clearly explained to participants before conducting the interview and informed consent was obtained from each participant.Data was kept confidential throughout the conduct of the study.

\section{Results}

\subsection{Socio Demographic Characteristics of Study Subjects}

Out of the total 422 study participants planned, 410 were participated in the study yielding a response rate of $97.2 \%$. More than half $(51.7 \%)$ of them were female. The mean age of respondents was $41.9(\mathrm{SD}=1.4 \mathrm{yrs})$. More than three fourth $(79.0 \%)$ of the participants were married. The majority $(88.5 \%)$ of the participants were orthodox Christian followers. Regarding the ethnic profile of study subjects, Majority (87.3\%) of them were Amhara in ethnicity. Concerning the educational status of study subjects, $57(13.9 \%)$ were unable to write and read. One hundred thirty six $(33.2 \%)$ were farmers in occupation. Half of them $(50 \%)$ had $\leq 500$ birr monthly income. See table 1 .

Table 2: Health profile of participant,FHH, 2012

\begin{tabular}{|c|c|c|}
\hline Variable & Frequency & $\begin{array}{l}\text { Percent } \\
(\%)\end{array}$ \\
\hline \multicolumn{3}{|l|}{ Duration of DM therapy } \\
\hline$<1$ year & 176 & $\begin{array}{l}42.9 \\
180\end{array}$ \\
\hline $1-2$ year & 74 & 18.0 \\
\hline $3-5$ year & 83 & 20.0 \\
\hline$>5$ year & 77 & \\
\hline \multicolumn{3}{|l|}{ Current medication } \\
\hline Insulin & 312 & 76.2 \\
\hline Metformine & 62 & 15.1 \\
\hline Glibenclamide & 34 & 8.3 \\
\hline $\begin{array}{l}\text { Glibenclamide and } \\
\text { Metformine }\end{array}$ & 2 & 0.5 \\
\hline \multicolumn{3}{|l|}{ Family history of DM } \\
\hline Yes & 44 & 10.7 \\
\hline No & 366 & 89.3 \\
\hline \multicolumn{3}{|l|}{ Other chronic illness } \\
\hline Yes & 102 & \\
\hline No & 248 & 60.5 \\
\hline \multicolumn{3}{|l|}{ Type of DM } \\
\hline Type I & 305 & 74.4 \\
\hline Type II & 105 & 25.6 \\
\hline \multicolumn{3}{|l|}{ DM association member ship } \\
\hline Yes & 30 & 7.3 \\
\hline No & 380 & 92.7 \\
\hline
\end{tabular}

\subsection{Health Profile of Study Subjects}

One hundred seventy six (42.9\%) of study subjects were on diabetes drug treatment for less than one year. Concerning the type of medication they were taking, more than three fourth $(76.2 \%)$ of the participant were taking insulin injection. One hundred sixty two (39.5\%) study subjects had additional one or more chronic illness. Out of the 162 subjects who had additional chronic illness, 89 (55.2\%) had hypertension, 17 (10.5\%) had dislipedemia, $21(12.8 \%)$ had cardiac disease and $3(1.6 \%)$ of them had renal diseases.Majority $(89.3 \%)$ had not family history of DM. Majority (92.7\%) of participants were not member of diabetic association found in their area. Three hundred five (74.4\%) study subjects had type I DM. See table 2.

\subsection{Knowledge Regarding Diabetes}

The mean (+SD) knowledge score of study subjects was $12.71( \pm 3.73)$ with a maximum possible score of 29 . Two hundred four (49.8\%) participants had good knowledge and 206 (50.2\%) participants had poor knowledge regarding diabetes.

More than half $(66.6 \%)$ of study subjects didn't know the definition of diabetes. Less than $5 \%$ study participants knew about risk factor relatedto alcohol and cigarette smoking. Nearly three fourth $(70 \%)$ of the study participants consider orally taken tablets and injection alone as treatment options and nearly $20 \%$ study participants knew about exercise and dietary management as a treatment option. The correct responses on complication of DM like hypoglycemia, nephropathy, retinopathy, and neurologic were $49.8 \%, 20.2 \%, 54.4 \%$ and $37.0 \%$ respectively. The correct responses on risk factor of DM like Hypertension, hyper lipidemia, sedentary life style, cigarette smoking and obesity were $59.5 \%$, $38.5 \%$, and $18 \%, 3.4 \%$ and $5.6 \%$ respectively.

Exercise and diet were reported as a life style modification for prevention of DM in 300(73.2\%) and 195(47.6\%) respondents respectively. However, less than $10 \%$ of study participants knew weight reduction as life style modification for prevention of diabetes related complications.

One hundred twenty seven (31\%) study participants had knowledge on advisable dietary intake. They reported that $10-20 \%$ carbohydrate (grains and fruits), 40-60\% proteins (meat, egg and fish), 20-30\% fat, small amount vitamins and minerals are advisable food for diabetic patients.

More than three fourth $(82.0 \%)$ of study participants knew about the importance of control of blood glucose to reduce complication of DM. Two hundred seventy two (62.7\%) knew the importance of control of blood pressure for prevention of DM complications.

One hundred ninety four $(42.3 \%)$ study subjects didn't know regarding the importance of screening of family members.

\subsection{Source of Information and Appraisal of Treating Doctors}

Majority, $(85 \%)$ of the respondents reported that their source of knowledge was medical staffs. The remaining participants sited friends and relatives,and media with $37(9 \%)$ and $6 \%$ respectively as their source of information.

The time their doctors devote for them was five minutes for $238(58 \%)$ patients, ten minutes for $110(27 \%)$ and more 
than ten minutes for $37(9 \%)$ of respondents.

Table 3: Frequency distribution of participants response on knowledge toward diabetes, FHH, $2012(n=410)$

\begin{tabular}{|c|c|c|}
\hline Variable & Frequency & $\begin{array}{l}\text { Percent } \\
(\%)\end{array}$ \\
\hline \multicolumn{3}{|l|}{ What is diabetes? } \\
\hline \multicolumn{3}{|l|}{$\begin{array}{l}\text { Diabetes is a raised blood } \\
\text { sugar only }\end{array}$} \\
\hline Diabetes is a disease which & 218 & 53.2 \\
\hline affects any part of the body & 139 & 33.9 \\
\hline I don’t know & 55 & 13.4 \\
\hline \multicolumn{3}{|l|}{ Identify risk factor for DM } \\
\hline Over eating & 262 & 63.9 \\
\hline Family history & 256 & 62.4 \\
\hline Eating too much fat and sugar & 144 & 35.1 \\
\hline Alcohol & 9 & 2.2 \\
\hline Cigarette smoking & 6 & 1.5 \\
\hline No response & 7 & 1.7 \\
\hline \multicolumn{3}{|l|}{ Know treatment options of DM } \\
\hline Injection/Insulin therapy & 284 & 69.3 \\
\hline Orally taken tablets & 192 & 46.8 \\
\hline Dietary management & 43 & 10.5 \\
\hline Exercise & 33 & 8.0 \\
\hline Don’t know & 31 & 7.6 \\
\hline \multicolumn{3}{|l|}{$\begin{array}{l}\text { Know symptom of poorly controlled } \\
\text { DM }\end{array}$} \\
\hline Passing lots of urine & 340 & 82.9 \\
\hline Loss of appetite & 285 & 69.5 \\
\hline Excess thirst & 250 & 61.0 \\
\hline Tiredness & 111 & 27.0 \\
\hline Weight loss & 12 & 2.9 \\
\hline Don’t know & 42 & 10.2 \\
\hline \multicolumn{3}{|l|}{$\begin{array}{l}\text { Know complications of DM, if not } \\
\text { treated }\end{array}$} \\
\hline Ophthalmologic & 223 & 54.4 \\
\hline Hypoglycemic & 204 & 49.8 \\
\hline Renal & 83 & 20.2 \\
\hline Neurologic & 37 & 9.0 \\
\hline Don't know & 56 & 13.7 \\
\hline No response & 3 & 0.7 \\
\hline \multicolumn{3}{|l|}{ Identify health risk factors for DM } \\
\hline Hypertension & 244 & 59.5 \\
\hline Hyper-lipidemia & 158 & 38.5 \\
\hline Sedentary life style & 74 & 18.0 \\
\hline Obesity & 23 & 5.6 \\
\hline Cigarette smoking & 14 & 3.4 \\
\hline Don’t know & 45 & 11 \\
\hline \multicolumn{3}{|l|}{ Know regarding life style modification } \\
\hline Exercise & 300 & 73.2 \\
\hline Dietary modification & 195 & 47.6 \\
\hline Weight reduction & 32 & 7.8 \\
\hline Don’t know & 34 & 8.3 \\
\hline No response & 13 & 3.2 \\
\hline \multicolumn{3}{|l|}{$\begin{array}{l}\text { Control of your blood glucose levels is } \\
\text { an important reducing Complication of } \\
\text { DM? }\end{array}$} \\
\hline Yes & 336 & 82.0 \\
\hline No & 74 & 18.0 \\
\hline \multicolumn{3}{|l|}{$\begin{array}{l}\text { Diabetes patient should measure his or } \\
\text { her B/P? }\end{array}$} \\
\hline Yes & 257 & 62.7 \\
\hline No & 153 & 37.3 \\
\hline
\end{tabular}

Table 4: Source of information, appraisal of their treating doctors and their need of information about diabetes among DM patients in FHH, 2012

\begin{tabular}{|c|c|c|}
\hline Question & Frequency & Percent (\%) \\
\hline \multicolumn{3}{|l|}{ Source of information } \\
\hline Medical staff & 348 & 85 \\
\hline Media & 25 & 6 \\
\hline Relatives and friend & 37 & 9 \\
\hline \multicolumn{3}{|l|}{$\begin{array}{l}\text { How much time your doctors } \\
\text { devote to you? }\end{array}$} \\
\hline Five minutes & 238 & 58 \\
\hline Ten minutes & 110 & 27 \\
\hline More than ten minutes & 37 & 9 \\
\hline \multicolumn{3}{|l|}{$\begin{array}{l}\text { Your doctor explains you diabetes } \\
\text { thoroughly? }\end{array}$} \\
\hline Yes & 238 & 58 \\
\hline No & 172 & 42 \\
\hline \multicolumn{3}{|l|}{ Does your doctor explain diet? } \\
\hline Yes & 221 & 54 \\
\hline No & 189 & 46 \\
\hline \multicolumn{3}{|l|}{ Does your doctor explain exercise? } \\
\hline Yes & 197 & 48 \\
\hline No & 213 & 52 \\
\hline \multicolumn{3}{|l|}{$\begin{array}{l}\text { How would you like this } \\
\text { information given to you? }\end{array}$} \\
\hline Handouts or leaflet & 332 & 81 \\
\hline Videos or tapes & 137 & 33.4 \\
\hline Other (please specify) & 5 & 1.2 \\
\hline
\end{tabular}

Among the total respondents, $54 \%, 48 \%, 32 \%$ received explanation about diet, exercise and regular checkup from health professionals. One hundred nineteen $(29 \%)$ of respondents reported thatthey received motivation from health professional about self-care. Foot care checking and self-care motivation, the two main aspects of diabetes care were ignored by most of the treating practitioners.

Among respondents $332(81.0 \%)$ and $137(33.4 \%)$ of them would like to receive information through leaflet and audio visuals respectively.

\subsection{Factors Associated with Knowledge Regarding Diabetes}

Age, marital status, education status, duration of DM cases, duration of DM therapy, types of DM and being DM membership were significant at 0.2 and were entered in to the final regression model. Age, educational status, duration of DM therapy and types of DM showed a significant association with good knowledge at a 5\% level of significance.

Participants who were in the age group of 18-32 yrs, 33$41 \mathrm{yrs}$ and $42-50 \mathrm{yrs}$ were 6.2 times $(\mathrm{AOR}=6.17,95 \% \mathrm{CI}$ : $2.89-13.18), 3.3$ times $(\mathrm{AOR}=3.29, \mathrm{CI}: 1.53-7.08)$ and 3.1 times $(\mathrm{AOR}=3.14,95 \%$ CI: $1.50-6.57)$ respectively more likely to have good knowledge as compared to individuals who were at the age of 50 and above.

Similarly, those participants were in grade 1-8, grade 9- 
12 and those who attended higher education and above were 3.4 times $(\mathrm{AOR}=3.41,95 \% \mathrm{CI}$ : 1.46-7.95), 4.7 times $(\mathrm{AOR}=1.92, \quad 95 \% \mathrm{CI}: 1.92-11.31)$ and 7.2 times ( $\mathrm{AOR}=7.24,95 \% \mathrm{CI}$ : 2.86-18.34) respectively more likely to have good knowledge as compared to those who were unable to read and write.

The likely hood of good knowledge among individuals who were on DM therapy for 3-5 years,> 5 years were 6 (AOR $=6.01,95 \% \mathrm{CI}: 1.2 .93-12.32)$ times and 6.3 times $(\mathrm{AOR}=6.34,955 \mathrm{CI}: 3.18-12.63)$ respectively higher compared to individuals who were on treatment for $<1$ year.The likelihood of good knowledge among individuals who had type II DM were nearly $47 \%$ less compared to individuals who had type I DM.

Table 5: factors associated with knowledge about diabetes, FHH, $2012(n=410)$

\begin{tabular}{|c|c|c|c|c|}
\hline Variable & $\begin{array}{l}\text { Knowledge } \\
\text { Good n (\%) } \\
\end{array}$ & Poor n (\%) & COR(95\% CI) & $\operatorname{AOR}(95 \% \mathrm{CI})$ \\
\hline \multicolumn{5}{|l|}{ Age category } \\
\hline $18-32$ & $74(70.5)$ & $31(29.5)$ & $6.98(3.81-12.79)$ & $6.17(2.89-13.18)^{* *}$ \\
\hline $33-41$ & $46(49.5)$ & $47(50.5)$ & $2.86(1.57-5.20)$ & $3.29(1.54-7.09)^{* *}$ \\
\hline $42-50$ & $57(53.8)$ & $49(46.2)$ & $3.40(1.90-6.08)$ & $3.14(1.50-6.57)^{* *}$ \\
\hline$\geq 50$ & $27(25.5)$ & $79(74.5)$ & 1 & 1 \\
\hline \multicolumn{5}{|l|}{ Marital status } \\
\hline Married & 161(49.7) & $163(50.3)$ & 1 & 1 \\
\hline Single & $18(38.3)$ & $29(61.7)$ & $0.63(0.34-1.18)$ & $1.82(0.81-4.07)$ \\
\hline Divorced/widowed & $25(64.1)$ & $14(35.9)$ & $1.80(0.91-3.6)$ & $2.2(0.98-5.03)$ \\
\hline \multicolumn{5}{|l|}{ Educational status } \\
\hline Unable to read and write & $12(21.1)$ & $45(78.9)$ & 1 & 1 \\
\hline Read and write & $16(30.2)$ & $37(69.8)$ & $1.62(0.68-3.85)$ & $1.27(0.46-3.51)$ \\
\hline Grade $1-8$ & $60(49.6)$ & $61(50.4)$ & $3.69(1.78-7.65)$ & $3.41(1.46-7.95)^{* *}$ \\
\hline Grade 9-12 & $66(63.5)$ & $38(36.5)$ & $6.51(3.07-13.81)$ & $4.66(1.92-11.31) * *$ \\
\hline Higher education and above & $50(66.7)$ & $25(33.3)$ & $7.5(3.38-16.65)$ & $7.24(2.86-18.34)^{* * *}$ \\
\hline \multicolumn{5}{|l|}{ Duration of DM therapy } \\
\hline$<1$ year & $51(29.0)$ & $125(71.0)$ & 1 & 1 \\
\hline $1-2$ year & $32(43.7)$ & $42(56.8)$ & $1.87(1.06-3.28)$ & $1.55(0.83-2.93)$ \\
\hline $3-5$ year & $61(73.5)$ & $22(26.5)$ & $6.79(3.78-12.21)$ & $6.01(2.93-12.32)^{* * *}$ \\
\hline$>5$ year & $60(77.9)$ & $17(22.1)$ & $8.65(4.61-16.23)$ & $6.34(3.18-12.63)^{* * *}$ \\
\hline \multicolumn{5}{|l|}{ Types of DM } \\
\hline Type I & $161(52.8) \quad 43$ & $144(47.2)$ & 1 & 1 \\
\hline Type II & $(21.1)$ & $62(59.0)$ & $0.62(0.39-0.97)$ & $0.53(0.29-0.94) *$ \\
\hline
\end{tabular}

$* \mathrm{p}<0.05 \quad * * \mathrm{p}<0.01 \quad * * * \mathrm{p}<0.001$

Table 6: Response to practice question about diabetes, FHH, 2012 (n= 410)

\begin{tabular}{lll}
\hline Variable & Frequency & Percent \\
\hline When was your B/P checked last? & & \\
One week ago & 43 & 10.5 \\
Within one month & 64 & 15.6 \\
Two month ago & 227 & 55.4 \\
Six month ago & 76 & 18.5 \\
When was your last urine exam & & \\
done? & & \\
Within one month & 78 & 19.0 \\
Two month ago & 112 & 27.3 \\
Six month ago & 134 & 32.6 \\
$\begin{array}{l}\text { One years ago } \\
\text { When was your last visit with your } \\
\text { physicians? }\end{array}$ & 21 & 5.1 \\
$\begin{array}{l}\text { One week ago } \\
\text { Within One month }\end{array}$ & 66 & \\
$\begin{array}{l}\text { Two month ago } \\
\text { Six month ago }\end{array}$ & 29 & 16.1 \\
When was your last Blood Sugar \\
checked?
\end{tabular}

\begin{tabular}{lll}
\hline Variable & Frequency & Percent \\
\hline One week ago & 19 & 4.6 \\
With in one month & 78 & 19 \\
Two month ago & 303 & 73.9 \\
Six month ago & 10 & 2.4 \\
Follow a dietary modification? & & \\
& 234 & 57.1 \\
Yes, many times & 67 & 16.3 \\
No, never & 109 & 26.6 \\
Yes, occasionally & & \\
Have you tried to lose weight in & & \\
the past? & 207 & 50.5 \\
Yes, many times & 123 & 30 \\
No, never & 57 & 13.9 \\
Yes, occasionally & & \\
When was your last eye & & \\
examination? & 12 & 2.9 \\
Within one month & 52 & 12.7 \\
Six month ago & 114 & 27.8 \\
Within one year & 74 & 18.0 \\
One years ago & 24 & 5.8 \\
Two years ago & 134 & 32.7 \\
Note done at all & & \\
\hline
\end{tabular}




\subsection{Practice on Diabetes}

The mean $(+\mathrm{SD})$ practice score of study subjects was $3.20( \pm 2.02)$. One hundred fifty four $(36.8 \%)$ participants had good practice and $256(63.2 \%)$ participants had poor practice regarding diabetes.

Among respondents, the last time to check $\mathrm{B} / \mathrm{P}$, urine exam and blood sugar with in one months or less were $26.1 \%, 19.0 \%$ and $23.6 \%$ respectively. Two hundred thirty four $(57.1 \%)$ participant were managing their diet regularly and $207(50.5 \%)$ participants were controlling their weight regularly. Among respondents 12(2.9\%) were checking their eye with in one month duration and 178(43.4\%) were checking their eye with in one years or less duration.

\subsection{Factors Associated with Practice on Diabetes}

Age, sex, religion, marital status, educational status, work status ,monthly income ,duration of DM ,duration of DM therapy, currentlyusing drug, family history of DM and types of DM were significant at 0.2 on binary regression model and were entered in to multivariate analysis.Age, sex, marital status, educational status, monthly income and duration of DM therapy maintained their significance in the multivariate analysis at a $5 \%$ level of significance.

Those who were in the age of $18-32$ were 6 times
(AOR=6.05, 95\% CI: 2.44-15.03) more likely to have good practice as compared to those who were in the age of $\geq 51$ years.The likelihood of good practice among female participants were nearly $54 \%$ less $(\mathrm{AOR}=0.45,95 \% \mathrm{CI}$ : $0.25-0.82$ ) as compared to male participants. The likelihood of good practice among widowed and divorced were nearly $90 \%$ less $(\mathrm{AOR}=0.10,95 \% \mathrm{CI}: 0.02-0.44)$ as compared to who were married.

Participants in grade $1-8$ were 3.5 times $(A O R=3.54,95 \%$ CI: 1.16-10.82), those in grade 9-12 were 4.3 times $(\mathrm{AOR}=4.27,95 \% \mathrm{CI}: 1.37-13.25)$ and those who had higher education and above were 5.4 times $(\mathrm{AOR}=5.45,95 \%$ CI: $1.67-17.82)$ more likely to have good practice as compared to those who were unable to read and write.The likelihood of good practice among individuals who had $\leq$ 500 Eth Birr income were nearly $85 \%$ less (AOR $=0.15,95 \%$ CI: 0.09-0.27) as compared to individuals who had $>500$ Eth. birr income.

Participants who were on DM therapy for 1-2 years were 2.8 times $(\mathrm{AOR}=2.86,95 \% \mathrm{CI}: 1.27-6.46)$, those who were treated for 3-5 years were 5.4 times $(\mathrm{AOR}=2.35,95 \% \mathrm{CI}$ : 2.35-12.55) and those who were treated for $>5$ years were 4.2 times(AOR=4.16,95\% CI: $1.85-9.37)$ more likely to have good practice as compared to individuals who were on DM therapy for $<1$ year.

Table 7: factors associated withpractice of DM patients, FHH, 2012

\begin{tabular}{|c|c|c|c|c|}
\hline Variable & $\begin{array}{l}\text { Practice } \\
\text { Good(\%) }\end{array}$ & Poor $(\%)$ & $\operatorname{COR}(95 \% \mathrm{CI})$ & $\operatorname{AOR}(95 \% \mathrm{CI})$ \\
\hline $\begin{array}{l}\text { Age category } \\
\qquad \begin{aligned} 18-32 \\
33-41 \\
42-50 \\
\geq 50\end{aligned}\end{array}$ & $\begin{array}{l}65(61.9) \\
42(45 . .2) \\
26(24.5) \\
18(17.0)\end{array}$ & $\begin{array}{l}40(38.1) \\
51(54.8) \\
80(75.5) \\
88(83.0)\end{array}$ & $\begin{array}{l}7.94(4.18-15.09) \\
4.03(2.10-7.72) \\
1.58(0.81-3.11) \\
1\end{array}$ & $\begin{array}{l}6.05(2.44-15.03)^{* * * *} \\
2.36(0.93-6.0) \\
1.32(0.51-3.46) \\
1\end{array}$ \\
\hline $\begin{array}{l}\text { Male } \\
\text { Female }\end{array}$ & $\begin{array}{l}81(40.9) \\
70(33.0)\end{array}$ & $\begin{array}{l}117(59.1) \\
142(67.0)\end{array}$ & $\begin{array}{l}1 \\
0.71(0.48-1.06)\end{array}$ & $\begin{array}{l}1 \\
0.46(0.25-0.82)^{* *}\end{array}$ \\
\hline $\begin{array}{l}\text { Educational status } \\
\text { Unable to read and write } \\
\text { Read and write } \\
\text { Grade } 1-8 \\
\text { Grade } 9-12 \\
\text { Higher education and above }\end{array}$ & $\begin{array}{l}6(10.5) 16(30.2) \\
42(34.7) \\
48(46.2) \\
39(52.0)\end{array}$ & $\begin{array}{l}51(89.5) \\
37(69.8) \\
79(65.3) \\
56(53.8) \\
36(44.4)\end{array}$ & $\begin{array}{l}1 \\
3.68(1.31-10.29) \\
4.52(1.79-11.39) \\
7.29(2.88-18.46) \\
9.21(3.53-24.04)\end{array}$ & $\begin{array}{l}1 \\
2.58(0.72-9.27) 3.54(1.16- \\
10.82)^{*} \\
4.27(1.37-13.25) * 5.46(1.67- \\
17.82)^{* *}\end{array}$ \\
\hline $\begin{array}{l}\text { Marital status } \\
\qquad \begin{array}{l}\text { Married } \\
\text { Single } \\
\text { Widowed/Divorced }\end{array}\end{array}$ & $\begin{array}{l}131(40.4) \\
17(36.2) \\
3(7.7)\end{array}$ & $\begin{array}{l}193(59.6) \\
30(63.8) \\
36(92.3)\end{array}$ & $\begin{array}{l}1 \\
0.83(0.44-1.57) \\
0.12(0.04-0.41)\end{array}$ & $\begin{array}{l}1 \\
1.28(0.47-3.47) \\
0.10(0.02-0.45)^{* *}\end{array}$ \\
\hline $\begin{array}{l}\text { Monthly income } \\
\qquad \begin{aligned} \leq 500 \text { Eth.Birr } \\
>500 \text { Eth.Birr }\end{aligned}\end{array}$ & $\begin{array}{l}37(18) \\
114(55.6)\end{array}$ & $\begin{array}{l}168(82) \\
91(44.4)\end{array}$ & $\begin{array}{l}0.18(0.11-0.28) \\
1\end{array}$ & $\begin{array}{l}0.15(0.09-0.27)^{* * * *} \\
1\end{array}$ \\
\hline $\begin{array}{c}\text { Duration of DM } \\
<1 \text { year } \\
1-2 \text { year } \\
\text { 3-5year } \\
>5 \text { year }\end{array}$ & $\begin{array}{l}43(24.4) \\
30(40.5) \\
47(56.6) \\
31(40.3)\end{array}$ & $\begin{array}{l}133(75.6) \\
44(59.5) \\
36(43.4) \\
46(59.7)\end{array}$ & $\begin{array}{l}1 \\
2.11(1.18-3.76) \\
4.04(2.32-7.02) \\
2.08(1.18-3.69)\end{array}$ & $\begin{array}{l}1 \\
2.86(1.26-6.46)^{*} \\
5.43(2.35-12.55)^{* * *} \\
4.16(1.85-9.37)^{* *}\end{array}$ \\
\hline
\end{tabular}




\section{Discussion}

This study was conducted with the intention to assess the level and associated factors with knowledge and practice about diabetic mellitus. The study showed that the mean $( \pm$ SD) knowledge score of study subjects was $12.71( \pm 3.73)$. Two hundred four (49.8\%) study participants had good knowledge regarding diabetes. This study had demonstrated lower level of knowledge regarding diabetes. The prevalence of knowledge was lower compared to studies done in Pakistan and Saudi which were $60 \%$ and $77 \%$ respectively $(7,9)$. This difference might be due to high illiteracy rate of the study participant, less devoted time with the patients by physicians, lack of organized diabetic education facilities and less participation of media and NGO in awareness creation about diabetes in our setting.

Two hundred eighteen (53.2\%) of the study participants thought that diabetes doesn'taffect all part of the body and is characterized by raised blood sugar only. This study was supported by similar study in Pakistan and India which reported that $54 \%$ and $57.8 \%$ of participant didn't know what diabetes mean $(7,20)$. Similarly, passing lots of urine which was reported as the most common diabetes symptom by $82.9 \%$ of participants was consistent with the study conducted in Indian (20).

Cigarette smoking is associated with poor control of blood glucose and strongly causally related to hypertension and heart disease in people with diabetes (20). However knowledge on risk factor of smoking and overweight was very low in this study. This could be due to inadequate level of information given by the physicians on risk factors and their consequences.

Another finding of this study was limited knowledge on complications related to DM. Knowledge about brain(Neuropathy) and renal (Nephropathy) complications were $9.0 \%$ and $20.2 \%$ respectively. This was consistent with the study conducted in Gujarat $5 \%$ and $25 \%$ respectively (12). However, this level of inadequate knowledge regarding risk factor and complication may lead to decrease precaution of patient for complication and these are high economic burden for the country in the management of complication which comes due to in adequate precaution for the complication. This finding highlights the need for emphasizing diabetic's complicationsduring diabetes education.

Most patients $(51.2 \%)$ did not realize the importance of screening the other family members for diabetes and according to some literatures this might probably indicates for a large number of people remaining undiagnosed (26).

In this study the main sources of information was health professional $(86 \%)$ which include nurses and physicians. This study was supported by study in Pakistan and Saudi which reported that health professionals was the main source of information in $78 \%$ and $68 \%$ of participants $(7$, 9).This finding indicated that medias contribution for diabetes related information was very low(6\%) compared to study in Gujarat (12). This indicated that a lot should be done for involvement of Medias in diabetes education.

The time devoted by the doctor for examination and counseling was less than 5 minutes in 58\% study participant. This is better than Pakistan study which was $65 \%$, however, this finding was higher compared to Gujarat study which was $43 \%(7,12)$. The difference with Gujarat study might be physician's spare very limited time for their patients due to the rush in the out-patient department and negligence.

The mean $( \pm \mathrm{SD})$ practice score of study subjects was $3.20( \pm 2.02)$. One hundred fifty four $(37.6 \%)$ participants had good practice and 256(63.2\%) study participants had poor practice regarding diabetes. This finding was lower compared to study conducted in Saudi (9).This difference may be due to high illiteracy rate of the study participants, lack of health care access, poor patient attendance at health clinics. Another explanation might be physician's barriers like constrain of time and facilities focus on acute rather than preventive care and competing care demands (20).

Among respondents, the last times to check their blood pressure within one months or less were $26.1 \%$.This study was different from study conducted in Nepal which was $66 \%$. This could be due to poor experience in the patient and business orientation and negligence of the physicians. The last time to check their urine exam with in one months or less were $19 \%$, which was slightly lower than the study done in Nepal which was $26.9 \%(16)$.Only $57.1 \%$ of participants managed their diet regularly which was supported by study in jimma university (17), However it was less compared to study conducted in India which showed that $82.8 \%$ of study participant had compliance to dietary modification (20). A study done in Saudi to assess KAP in women toward diabetes mellitus showed $16 \%$ were not at all following the dietary plan. Poor state of practice regarding nutrition has also been reported in several other studies $(18,19)$.

Among respondents $50.5 \%$ were controlling their weight regularly. This finding was lower than the study conducted in Pakistan which was $66 \%$.This could be due to low knowledge about the importance of managing their weight in reduction of complication and less dietary management and exercise experience by the patients.

Lower age was significantly associated with knowledge. This finding was supported by other different literatures (11, $22,25)$ and with West and Goldberg principles which reported that a decrease of $3 \%$ in the knowledge score of diabetic patients for every 10-year increase in age (27).This could be due to older persons have less education, worse cognitive function and have more co-morbidities, which might lead to confusion (25). Another explanation might be younger patients were more likely to be more educated, faster in remember and recall and they might be new sufferers of diabetes and they were eager to have more knowledge about their disease (22).

Good knowledge had a significant association with 
educational status of the respondent.This finding was in line with different studies conducted in different countries $(10,11,22,23$, and 24).This could be explained by respondents who had at least primary educational status have higher chance of exposure to different IEC material like leaflet, manual and that they have no barriers in communicating with the health care team beside their potential to grasp information's already communicated (22).

The likely hood of good knowledge increases with increasing in duration of DM treatment. This finding was not inline with West and Goldberg study, who found no significant increase in knowledge scores with the number of year patients started treatment(27). However,this finding was consistent with study conducted in South Africa and Nigeria $(11,25)$. This could be due to frequent contact with health provider which creates opportunity to get information regarding diabetes. The difference with USA finding might be due to the difference in access for information between countries during the course of treatments (24).

Those participants who were in the age of 18-32 had 6 folds increase in practice level compared to age $>50$. This could be attributed to lack of motivation and lack of social support in elderly individuals compared to young adults. Social supports are vital for patient empowerment which would enable them to have a better understanding and selfmanagement of their illness (30).

The likely hoods of good practice among females were nearly $54 \%$ less compared to male participants. This finding was consistent with study in Egypt, India and Pakistan (7, 22, and 29). This might be due to high level of illiteracy among the females and less self-empowerment and social status in females. Another explanation could be women have low priority to health care seeking and present late for checkupwhen compared to men.

Educational status had significant association with good practice like that of knowledge. This finding was consistent with study in Egypt (22). This could be attributed that participant who had education have good chance to modify their life style and their health status by finding different alternatives for checkup. Educated people may also have better income better income status. This could also be their accessibility for manual of dietary management, weight reduction increases.

Good practice among respondents who had $\leq 500$ Eth Birr income was lower compared to respondents who had $>500$ Eth.birr incomes. This finding was consistent with study conducted in Gujarat and Malaysia $(12,30)$. This might be explained by participant who had low income, cannot afford to check up in private clinic without waiting the regular consultation time arranged by the hospital.They could also difficulty to manage their diet properly because of affordability issues. Moreover, Resources are necessary for sustained life style modification or behavior change and lack of resources could be a barrier for life style modification.

Duration of diabetes treatment was positively associated with practice. This finding was supported by Nigerian finding (25). This could be due to continued counseling and health education programs.

\section{Conclusion}

This study revealed a low level of knowledge and practice among the diabetes patients.

Age, Educational status, duration of DM therapy and DM types were the factors associated with good knowledge of participants. Ages, Sex, educational status, marital status, monthly income, duration of DM therapy were the factors associated with good practice of participants.

\section{Recommendation}

Both literate and illiterate people tailored I.E.C materials on diabetes symptom, risk factors, complication and life style modification for diabetic patient should be developed and disseminated.Establishing mechanisms where by diabetics patient with different age group, educational status and duration of DM therapy share their experiences is valuable.Media and non-governmentorganization involvement to enhance knowledge and practice about DM is highly recommended.Research with different settings by considering larger sample sizes arealso advisable

\section{Limitation of the Study}

The following are some of the limitations of this study.The study design it applied; as cross-sectional studies are poor in establishing temporal relationships between cause and effect and the fact that it was conducted among the outpatients in only one hospital could limit our understanding regarding knowledge and practice of the general diabetic population in the region.

\section{Abbreviations}

AOR, Adjusted Odds Ratio; CI, Confidence Interval; COR, Crude Odds Ratio; DM, Diabetes Mellitus; FHH, Felege Hiwot Hospital; GUH, Gondar University Hospital; IEC, Information, Education and Communication; IRB, Institutional Review Board; KAP, Knowledge, Attitude and Practice; OR, Odds ratio; SD, Standard deviation; WHO, World Health Organization

\section{Competing Interests}

The authors declare that they have no competing interests.

\section{Authors' Contributions}

SA contributes in the design, data collection, and data entry and also made the data analysis and interpretation of 
the data. CM also contributed to the data analysis, interpretation and write up of the manuscript. HT made intelectual review of the paper. All authors critically revised the manuscript and have approved the final manuscript.

\section{Acknowledgment}

We would like to forward our deepest gratitude to Felege Hiwot hospital for their support and facilitation of this research. We appreciate our friends for their moral and technical support. We are also grateful to the data collectors and we also thank all the patients who participated in the study.

\section{References}

[1] Fauci, Braunwald, kaiser, Longo, James et al. Harrison's principles of Internal medicine. 17th ed.United States of America. The McGraw-Hill companies; 2008.

[2] Motala AA, Omar MA, Pirie FJ. Diabetes in Africa. Diabetes micro vascular and macro vascular disease in Africa. J Cardiovascular Risk 2003; 10(2).

[3] Healthcare in Ethiopia, http://www.moh.gov.et/; http://www.ethiomedic.com/(

[4] AlemuS,DessieA,SeidE,BardE,LeePT,TrimpleER,et al.Insulin requiring diabetes in rural Ethiopia, Should we reopen the case for malnutrition -related diabetes?Diabetologia, 2009:52(1842-1845).

[5] Gill GV, Mbanya JC, Ramaiya KL, Tesfaye S.A sub Saharan African prospective of diabetes, Diabetologia, 2009:52(816).

[6] Cohen MP et al. High Prevalence of Diabetes in Young Ethiopian Immigrants Israel, Diabetologia 1988; 37:824-827.

[7] Naheed G. Knowledge, Attitudes and Practices of Type 2 Diabetics Mellitus, J Ayub Med Coll Abbottabad. 2010:22(3).

[8] Okolie, Uchenna

Ehiemere,IjeomaO,Ihanacho,Peacen,etal.Knoweledge of diabetes management and control by diabetic's patients at Federal Medical Center UmuahiaAbia State Nigeria. International Journal of medicine and Medical sciences.2009:1(9).

[9] Saadia Z Rushdie, Alsheha M, SaeedH, Rajab M.A .study of knowledge, Attitude and Practices of Saudi Women towards Diabetes Mellitus a (KAP) study in Al- Qassim Region, The Internal Journal of Health.2010:11(2)

[10] Maina WK, NdegwaZM,Njenga EW, Muchemi EW. Knoweledge, attitude and Practices related to diabetes among community members in four provinces in Kenya, Pan African Medical Journal.2010:7(2).

[11] Moodley L, Rambiritch V. An assessment of the level of knowledge about diabetes mellitus among diabetic patients in a primary healthcare setting, SA Fam Practice.2007:49(10).
[12] Viral N, Shah P, Kamdar K, Nishit S. Assessing the knowledge, attitudes and practice of type 2 diabetes among patients of Saurashtra region, Gujarat Int J Diabetes Dev. 2009 Jul-Aug; 29(3): 118-122.

[13] Gunay T, Ulusel B, Velipasaoglu S, Unal B, Ucku R, Ozgener N. Factors affecting adult knowledge of diabetes in Narlidere Health District, Turkey, 20(pub.med)

[14] Kheir N, Greer W, Yousif A, Al Geed H, Al Okkah R. Risk factors, knowledge and health status in diabetic patients. Saudi Med J 2003: 24 (11).

[15] Kheir N, Greer W, Yousif A, Al Geed H, Al Okkah R. Knowledge, attitude and practices of Qatari patients with type 2 diabetes mellitus.

[16] Dineshk,subishP,RavisS,Paranaya. Knowledge, attitudes and practice about diabetes among diabetes patient in western Nepal. Rawal Med J 2008; 33:8-11.

[17] Hailu E, Mariam WH, Belachew T, Birhanu Z. Self-care practice and glycemic control amongst adults with diabetes at the Jimma University Specialized Hospital in south-west Ethiopia: A cross-sectional study. Afr J Prm Health Care Fam Med. 2012; 4(1).

[18] Upadhyay DK, Palaian S, Shankar PR, Mishra P. Knowledge, Attitude and Practice about Diabetes among Diabetes Patients in Western Nepal.Rawal Med J 2008; 23(1):1-12.

[19] Rafique G, Azam SI, White F. Diabetes knowledge, beliefs and practices among people with diabetes attending a university hospital in Karachi, Pakistan. East Mediterr Health J 2006; 12(5): 590-8.

[20] Mukhopadhyay, et.al: perceptions and practice of patients with diabetes mellitus type II.Int J DiabDev/July-September 2010/30/3.

[21] Sandeeps,GanesanA,MohanV.Development and updated of the diabetes atlas of India.Madras Diabetes Research foundation, Chennai.

[22] Naglaa MA, Mohamed EM .Effectiveness Of Health Education Program for Type 2 Diabetes Mellitus Patients Attending Zigzag University Diabetes Clinic, Egypt. Egypt Public Health Assoc. Vol. 85 No. 3 and 4,2010.

[23] KhaldonK.,Mohammad H., Fares H ,Ibrahim I. Diabetes Knowledge among Patients with Diabetes Mellitus at King Hussein Hospital .JRMS March 2012; 19(1): 72-77.

[24] Baradaran H, Knill JR .Assessing the knowledge, attitudes and understanding of type 2 diabetes amongst ethnic groups in Glasgow, Scotland PractDiabInt May 2004 Vol. 21 No. 4.

[25] Maxwell O., Cletus N., Chinwe V., Jegberime M, ObinnaP.Diabetes self-care knowledge among type 2 diabetic outpatients in south-eastern Nigeria, IntJ.Drug Dev.\& Res. | Sept-December 2009 | Vol. 1 | Issue 1 | 85.

[26] Abera E. Patterns of chronic complications of diabetic patients in Menelik II Hospital, Ethiopia.Ethiop.j.Health dev.2000;14(1):113-116

[27] West JD, Goldberg KL. Diabetes self-care knowledge among outpatients at a veteran's affairs medical center. American Journal of Health-system Pharmacy 2002; 59 (9):849-52. 
120 Solomon Asnakew Feleke et al:: Assessment of the Level and Associated Factors with Knowledge and Practice of Diabetes Mellitus among Diabetic Patients Attending at FelegeHiwot Hospital, Northwest Ethiopia

[28] $\mathrm{Hu}$ J,GruberK,LiuH,Zaho H, Garcia A.Diabetes knowledge among older chinese adults with diabetes in Beijing,China.Journal of Clinical Nursing,2013,22(1-2),5160.

[29] Shrestha A, Kosalram K, GopichandranV.Gender Difference in Care of Type 2 Diabetes, .JNMA Nepal Med Assoc, 2013; 52(189):245-50.
[30] AmudhaK.Knoweledge, attitude and practice among diabetic patient in Malysia.International journal of collaborative research on internal medicine and public health.2012.4 (5). 